\title{
A Comparison between the Methodology of Recording History of Ancient Historians
}

\author{
Qihan Long \\ BA History, Royal Holloway University of London, Surrey, TW20 0EX, England
}

Keywords: Ancient Historians, Recording History, Sima Qian

\begin{abstract}
Chinese and western historiography have their long historical traditions. They not only shown many common features, but also formed various distinctive differences during its development for thousands of years. This paper compares the most famous three ancient historians, who are Herodotus, Thucydides and Sima Qian. Herodotus traveled to different places to write down the deeds of human kind. He recorded as many things as possible was not because of the lack of consideration of the accuracy of the sources, but because of the possibilities of losing the truth during the process of selecting sources. Thucydides, on the other hand, was extremely paranoid about the accuracy of his sources. He was not tolerant to any possible mistake in his book. Sima Qian was a combination of Herodotus and Thucydides. The accuracy and reliability of the sources had been under the primary concern of historians since the ancient time.
\end{abstract}

\section{Introduction}

History, as one of the most important components of a nation, could not be simply ignored. In fact, no nation could make progress without its own history. Just as the famous phrase stated "standing on the shoulders of giants", the development of a state or society was based on what have been developed. History is also a subject of wisdom. As famous historian Sima Qian mentioned "history could enable one to view the connection between heaven and human, and understand how the past and present processed". Through learning history, one could make himself wise by avoiding the mistakes that had been made before. It is a mirror that reflects the past, present and future. As the second emperor of the Tang dynasty, Li Shimin, one of the greatest emperors in Chinese history, stated “one could trim one's apparel through the mirror of brass; one could learn one's mistakes through the mirror of people; one could understand the rise and fall of empires through the mirror of history". Therefore, the accuracy of history would be extremely crucial for the state and the individual who study it. The pioneers of historians had already realized the significance of the accuracy of sources. Instead of creating useful truth for their own belief and the sake of state, they worked hard to reveal what actually happened. This essay will examine the methods of three ancient historians, Herodotus, Thucydides and Sima Qian respectively.

\section{Comparison between the Methodology of Recording History of Ancient Historians}

Herodotus was born at Halicarnassus, the south-west coast of Asian Minor, in 484 BC. His natural born curiosity and responsibility of preserving the deeds of human kind pushed him to complete his famous book of history. He traveled to various places, from the Persian Empire, to many places in Greece, to North Africa, and to southern Italy. Through his traveling, he documented every single valuable story that he heard. With his nature of inquiry, Herodotus tried to find out the causation of history. "Why does the Nile flood? Why were the Dodona priestesses called dove? That is the sort of question Herodotus asks". Some criticized him for not considering the accuracy of his documents; nevertheless, Herodotus recorded as many sources as possible was not due to the lack of consideration of accuracy of the sources, but to the purpose of best preserve about what happened in the past. For the stories in the remote places, they were impossible for Herodotus to prove and 
analysis. Therefore, the best way to preserve history was to record all of the stories. Though not all the stories could be the actually facts; however, some of them could be true. If Herodotus choose not record those stories, a large amount of valuable sources could be lost. As Herodotus said himself, "I went as far as Elephantine to see what I could with my own eye, but for the countries further south I had to be content with what I was told in answer to my question". Besides the reason of the limitation of accessibility, there was another good reason for Herodotus to record the stories that he heard. The oral traditions continually handed down on a large scale, even since the introduction of the writing system. The oral stories, though, sometimes might be inaccurate, contained a large amount of valuable sources about the past. Many histories passed down through the stories. It is true that many stories in the oral tradition were exaggerated, dramatized and sometimes untrustworthy; however, they contained what actually happened in some case. It would be foolish to ignore all of them as a historian. A smart way would be record all of them as Herodotus did. Herodotus stated "my business is to record what people say. But I am by no means bound to believe it”. It was the words that created controversy and misinterpretation, since many people argued that Herodotus did not care much about the accuracy of his sources. In fact, when Herodotus read the book of Hecataeus, "the first thing he did was to ask whether the tradition recorded by Hacataeus was true". If Herodotus did not worry about the accuracy of his sources, he would not ask whether the records of Hacataeus were true; nor would he traveled to decades of Greek states to cite verbal reports. The artistic writing style of Herodotus brought him many criticize from later historians. But, because of this writing style, he brought history to alive. He vividly described the things happened in the past, making the stories intriguing to the readers. Therefore, the general public would seek their root of origin and take the lessons from history. Herodotus' tolerance to the Persian "barbarian" was due to his cheerful broad-mindedness. He made mistake about doubting the land crossing Sahara; however, his description of the embalming of corpses of the Scythians has been amazingly proved by the discovery of royal tombs in the Kuban. His record of the ants larger than dog might be the marmots in the border between India and China. He incredibly portrayed the matriarchal society in Asia, and his long account of Egypt proved to be an acute and conscientious survey. He was the first historian who recorded history beyond the border of states and embraced various cultures. He was the first man who sought for the causation of events and history in the European history and connected history with geography. He gave a clear explanation of the importance of sea power to the Greek. Since the Persian could land at any spot alone the coast, the building of a defensive wall on the land would be pointless. His sources could not be blame for lack of accuracy. In the contrary, they were the evidences of the zeal of Herodotus to preserve the truth of history. Therefore, Herodotus was somehow more than a historian, who was a preserver of the time.

Thucydides, on the other hand, tended to be more selective and critical about his sources. He did not simply record what he had been told, but examined the sources critically and objectively before he wrote them down. His approach to the history was more resemble to the modern historians in certain extent. A good side of this way of approach would be it could possibly eliminate the bias views of eye-witnesses. Since "different eye-witnesses give different accounts of the same events, speaking out partiality for the one side or the other or else from imperfect memories”. It is human nature to view things from one's subjective perspective. A single event could mean different things for different people. They could intemperate it in different ways and add their understanding to dramatize the story. Thus a single story could be developed into different versions. As Thucydides said "with regard to my factual reporting of the events of the war, I have made it a principle not to write down the first story that came my way, and not even to be guided by my own general impressions. I have checked with as much thoroughness as possible”. He tried extremely hard to be impartial about his works, trying to create an absolute accurate historical book. Ironically, because of his effort of being absolute impartial and documenting the significant things in his mind, many valuable sources had been lost. For instance, he did not document that the tributes were raised in 425-424 BC. The increase of the tribute indicates that the reserves were low. He considered that the epigraphy and numismatic were not significant enough to be documented. Nor would he record the anecdotes that he considered as insignificant. If the historians' mission is to convey the truth of history, Thucydides' selective 
method, however, prohibited truth to be pass down through history in certain extent. For example, he documented the symptoms of disease that spread in Athens between 430BC and 429BC. For the reason that he realized none of the remedies of that time was universally efficacious, he did not record the components of the remedies. Even if none of the remedies was universal applicable, it would be crucial for the later historians and doctors to examine the medical condition during that time through those remedies. Every aspect of the society matters for the later scholars to study the past. Furthermore, beside the truth that had been considered as insignificant by Thucydides, Thucydides could possibly make errors in his process of selecting sources. Some facts might seem to be unrealistic, while some lies might seem as the truth. Therefore, it was almost inevitable to make mistakes in the process of choosing reliability. Compare with Thucydides, Herodotus's way of approach was wiser when facing with the uncertainties; however. Just because Thucydides' method could lead to the losing of valuable truth, it does not mean that Thucydides did not care about the accuracy of his book. In fact, the method of Thucydides was very similar with the method of contemporary natural science. His meticulously analytic method could be applied to the field of science as well. He clearly pointed out "people are inclined to accept all stories of ancient time in an uncritical way-even when these stories concern their own native countries". The deepest reason behind his scientific approach was the concern over the accuracy of the sources.

Sima Qian was a historian lived in the Han Empire of China (around 100BC). Before his birth, China experienced a devastating destruction of classical literature. The first emperor of China, who built the first Chinese empire in 221BC, burned a massive amount of classical books during his reign. It was probably one of the reasons for Sima Qian's father to re-construct the Chinese history. Sima Qian's father told Sima Qian that his ancestors had been written history for centuries as historians. He wished his son could complete his work of history. Sima Qian's father spoke to him "500 years after the Duke of Zhou passed away, there was Confucius who taught the people the way of the sages. Now it had been another 500 years. How can you not feel obligate to do something”? The Duke of Zhou was a model politician during the early Zhou dynasty. He assisted his nephew, King Cheng, to rule over the country and consolidated Zhou's regime through the feudal system. He was famous for his mercy to the public and loyalty to his nephew, the king. He built the political system of Li(礼, ritual) and Yue(music). Li stood for the social order, while Yue amused people. This system was Confucius' idea political system. Unlike Herodotus who sought for the causation of events, Sima Qian worked on preserve what happened and the idea of former philosophers. Since the causation of why things happened had been explained by numerous philosophers during the Spring and Autumn (770-476BC) and Warring States (475-221BC) period, there would be no need for Sima Qian to create a new theory. In fact, in Qian's autobiography of his masterpiece, Shiji, he compared the ideas of five major philosophers, Laozi, Mozi, Confucius, Shangyang and Xun zi respectively, indicating Qian mastered the ideas of those philosophers. Besides comparing those philosophies, Sima Qian made comments about the philosophies. He wrote "the golden pyramid of Confucius shall not be abandoned. The concept of wu wei (doing nothing against the big Dao, or the natural trend) of Daoism is hard to be explained, but easy to be utilized". The golden pyramid of Confucius indicates the idea society in Confucius value. In which the society functions like a pyramid with social orders, classes and a lot of mobility. The concept of wu wei is a Daoism strategy of managing a country. Those comments required the deep understanding of those philosophies, proving Sima Qian could master the classical at the age of ten according to himself. Sima Qian traveled to various places within the Han's border, such as Anhui, Shangdong and Hunan, to collect sources and learn the local cultures at the age of twenty. The way he wrote his history resemble to the combination of Herodotus and Thucydides. He did try to preserve as much sources as possible, while made his own analysis to them. The fact that he mastered the ancient classical and philosophies made his book even more valuable, since he could examine the sources carefully and match with the time through comparing the way of people talking and the philosophic ideas behind the sources. His experience of travelling and learning could add more credit to his masterpiece. Since he learnt the cultures from various places, when he needed to write the biography of a particular figure from particular region, he could apply his knowledge of the 
culture about that region to select the more reliable sources. His mastering of classical Chinese philosophies was even more crucial for him to check the reliabilities of his sources. Cause when writing about the important figures in the history, especially the politicians, philosophers, scholars and reformers, the ideology and personal principals of those people could be reflected in their actions and words. For instance, if Sima Qian found the words and actions of certain people did not match their personal beliefs in certain sources, he might not use those sources. Like Herodotus did, Sima Qian traveled to numerous places to collect sources; however, he did not bother to find out the causation of events, since it had been explained by various philosophies before him. He took his advantages of mastering classical Chinese literature and philosophies and knowing the cultures and customs of various places to analysis and comment his sources like Thucydides did. He successfully brought the Chinese history to alive after numerous books had been burned by the first emperor of China. He was both a preserver of the time and a philosophical thinker who analyzed and commented his sources.

\section{Conclusions}

In conclusion, history is an unalienable part of every country. It is a subject of glory and wisdom. If a country ignored its history, not only it would lose its proud deeds of its past, but also it would not make a wise decision when it face the similar problems with the past. Emperor Taizong of the Tang dynasty built an unprecedented empire in the Chinese history because he learnt the mistakes from the past. Therefore, the accuracy of history had been under the primary concern since the ancient time. Herodotus traveled to different places to write down the deeds of human kind. He recorded as many things as possible was not because of the lack of consideration of the accuracy of the sources, but because of the possibilities of losing the truth during the process of selecting sources. He did a great job as a preserver of human deeds. Thucydides, on the other hand, was extremely paranoid about the accuracy of his sources. He was not tolerant to any possible mistake in his book. Sima Qian was a combination of Herodotus and Thucydides. He traveled to many places as Herodotus did to collect sources, while did his own analysis on the sources like Thucydides did. Yet, he was also a great philosophic thinker how had his own opinions on the ancient Chinese philosophies. If the history was created for the purpose of useful truth to any individual or the sake of states, it would lose its value of glory and wisdom. Thus, the accuracy and reliability of the sources had been under the primary concern of historians since the ancient time.

\section{References}

[1] Chen Xin. Historians and Readers: On the Subject in Historical Cognition [J]. Fudan Journal (Social Sciences Edition), 2018(2): 18-27.

[2] Li Weifang. Studies by Western Historians on the Legalization of Civic Morals in the Ancient Roman Republic [J]. Chongqing Social Sciences, 2018(3): 109-116.

[3] Shi Jianxiong, Ma Ke. Ancient and Present: Academic Study of Historian HUANG Zhen of Southern Song Dynasty and the Realistic Consideration [J]. Seeking Truth, 2018(2): 143-152.

[4] You Qingchao. The Influence of Sima Qian's Family Background on Records of the Grand Historian [J]. Journal of Harbin University, 2017, 38(9): 71-73. 